\title{
Estilos de Aprendizagem e Facebook: Um experimento metodológico
}

\author{
Facebook and Learning Styles: A Methodological Experiment
}

SPADA, Daniele; Doutoranda; PUC-RIO

ccearte@gmail.com

COUTO, Rita Maria de Souza; Doutora; PUC-RIO

ricouto@puc-rio.br

RIBEIRO, Flávia Nizia; Doutora; PUC-RIO

flavianizia@gmail.com

\section{Resumo}

Ao aproximar Estilos de Aprendizagem e Facebook, este artigo pretende mostrar a importância e valorização dos experimentos pedagógicos para inovação no ensino de design. Mudanças metodológicas, aparentemente pequenas, podem produzir resultados positivos na construção do conhecimento. Estas mudanças precisam ser compartilhadas, aperfeiçoadas e enriquecidas mediante a troca acadêmica e científica entre pares do campo do design. Para que esta troca ocorra, este artigo apresenta a documentação do processo e coleta de dados pelos quais, podemos comunicar os resultados a serem validados ou refutados, contribuindo assim, para a inovação em contextos educacionais. A primeira parte do artigo discorre sobre os Estilos de Aprendizagem Felder-Soloman (EAFS) e suas implicações no ensino de design; a segunda parte apresenta o experimento metodológico e a estrutura proposta a realização; por fim, é apresentada uma reflexão sobre os resultados obtidos e o apontamento de novos caminhos traçados para o ensino de design.

Palavras-chave: experimento; aprendizagem; Facebook.

\begin{abstract}
When approaching Learning Styles and Facebook, this article intends to show the importance and valorization of the pedagogical experiments for innovation in the teaching of design. Methodological changes, apparently small, can produce positive results in the construction of knowledge. These changes need to be shared, improved, and enriched through academic and scientific exchange among peers in the design field. For this exchange to occur, this article presents the process documentation and data collection by which we can communicate the results to be validated or refuted, thus contributing to innovation in educational contexts. The first part of the article discusses the Felder-Soloman Learning Styles (EAFS) and their implications for design teaching; the second part presents the methodological experiment and the structure proposed the realization; finally, a reflection on the results obtained and the identification the identification of new paths traced to the teaching of design.
\end{abstract}

Keywords: experiment; learning; Facebook. 


\section{Introdução}

Este artigo surgiu da necessidade de documentação de um experimento pedagógico realizado desde fevereiro de 2016: Os Estilos de Aprendizagem Felder e Soloman e o Facebook como plataforma colaborativa de aprendizagem na disciplina Arte Moderna e Contemporânea. A organização deste experimento deu-se através de pesquisas e experimentações apoiadas nos Estilos de Aprendizagem de Felder e Soloman (1991), cujo objetivo era oportunizar uma autonomia no processo de ensino-aprendizagem no campo do design.

No desenvolvimento desta metodologia baseada nos Estilos de Aprendizagem (EAFS) no Facebook, os estudantes puderam ter contato com os conteúdos da disciplina através da diversidade de recursos didáticos, oportunizando a saída da passividade e a mudança para o centro do seu próprio processo de aprendizagem. O maior desafio deste experimento foi incorporar este modelo ao ensino formal mantendo a liberdade que as Redes Sociais oferecem.

Estas alternativas envolveram a mudança de atividades institucionais para além da dinâmica de sala de aula. Envolveram a pesquisa, o estudante como pesquisador ativo; o processo de compartilhamento de saberes, fazer o aluno pensar e pensando juntos trocar as reflexões na construção do conhecimento e comunicar esses achados; o processo de avaliação, fundamentado na escolha do aluno, valorizando sua autonomia.

Antes do experimento proposto neste artigo, as aulas na referida disciplina já contavam com a postura do aluno pesquisador onde a preparação das aulas era feita pelos próprios estudantes. A sala de aula invertida preparada e apresentada por eles, foi o suporte necessário para esta construção metodológica.

A nova abordagem pedagógica encontrou no Facebook um lugar de trocas e compartilhamentos que permitia a flexibilidade de linguagens em uma comunicação síncrona e assíncrona necessárias para favorecer as dimensões dos Estilos de Aprendizagem. A escolha do Facebook se deu por dois motivos. Primeiro, o Facebook ainda é a rede mais popular e mais disseminada entre os estudantes, favorecendo assim o contato contínuo entre os estudantes através da tecnologia mobile. Segundo, as funções do Facebook. A rede social permite criar grupos, fazer postagens de imagens, vídeos, textos, links, lives, músicas, criar eventos, além das opções curtir, compartilhar, comentar, anexar gifs e memes, entre outras. No Facebook foi possível o pensamento compartilhado e colaborativo.

Os resultados deste experimento, até o momento, mostraram que, oferecer recursos diferenciados e estimular o sujeito para colaboração e compartilhamento do seu próprio processo, ele se torna autor de sua própria forma de fazer, proporcionando o nascimento de novas ideias e estruturas para compor uma nova forma de pensar, podendo assim, contribuir para sua formação discente bem como pessoal e profissional, além de desenvolver a capacidade colaborativa de construção de conhecimento. 


\section{Estilos de Aprendizagem Felder-Soloman (EAFS)}

O capítulo III da Constituição Federal de 1988, art. 206 garante, entre os princípios descritos, a liberdade de aprender, ensinar, pesquisar e divulgar o pensamento, a arte e o saber; o pluralismo de ideias e de concepções pedagógicas. Partindo destes princípios entendemos a necessidade da construção de práticas pedagógicas que auxiliem no processo de aprendizagem dos estudantes, neste caso, estudantes de Design. Práticas estas que possam auxiliar na formação de estudantes criativos, pensantes, pesquisadores e capazes de se tornar agentes na construção e comunicação do conhecimento. Para o desenvolvimento desta nova proposta pedagógica, as pesquisas sobre os Estilos de Aprendizagem Felder e Soloman (1991) foram valiosas.

No ano de 2015 as aulas eram ministradas sem a aplicação dos estilos de aprendizagem. As aulas eram realizadas em sala de aula invertida, mediadas por imagens, textos e vídeos. No final do período de 2015, uma questão trouxe um incômodo: o elevado número de alunos em prova final e reprovados na disciplina Arte Moderna e Contemporânea. A turma do período noturno contava com vinte e cinco alunos, apenas dez foram aprovados nas avaliações regulares. Quinze alunos foram para a prova final e destes quinze, nove foram reprovados. Um número alarmante. A turma diurna, no mesmo período, contou com quarenta e seis alunos, vinte e nove aprovados em situação regular, dezessete foram para prova final e destes, nove foram aprovados. A turma do período diurno apresentou melhores resultados em relação a turma do período noturno e mereceu uma atenção mais detalhada. Quando o levantamento de atividades foi feito, constatou-se que a turma da manhã havia participado de atividades diferenciadas como o "Cine Design", evento que contava com exibição de filmes e debate com convidados ao final da exibição, e participou de um grupo de estudos onde foi construído um grande mapa conceitual dos assuntos abordados durante as aulas. Estas ações revelaram que os alunos aprendem de formas variadas e quanto mais recursos forem oferecidos, maiores as chances de produção de conhecimento.

Esta análise dos dados suscitou a busca por novas propostas pedagógicas que pudessem estimular autonomia, responsabilidade e multiplicidade no processo de aprendizagem, bem como promover maior desempenho dos estudantes; e assim, os Estilos de Aprendizagem de Felder e Soloman foram muito bem-vindos neste processo. Após o estudo de alguns modelos, tais como Dunn, Dunn e Price (1982) que afirmam que os estilos de aprendizagem são as diferenciadas formas pela qual o sujeito conhece e desenvolve-se no mundo tanto físico, emocional e socialmente, absorvendo, processando e retendo informações; Hunt (1979), que defende estruturas capazes de permitir maior zona de conforto para que o estudante possa gozar da aprendizagem; Kolb (1984) com seu Inventário de Estilos de Aprendizagem que classifica a aprendizagem em Experiência Concreta, Conceituação Abstrata, Observação Reflexiva e Experimentação Ativa e Gregorc (1979) com seu Style Delineator (GSD) - percepção do ser humano classificando quatro estilos de aprendizagem: Sequencial Concreto, Sequencial Abstrato, Aleatório Abstrato e Aleatório Concreto; Fleming (2001) que desenvolveu o método VARK - (Visual, Aural, Read/ Write and Kinesthetic) que utiliza entrevistas, listas de verificação e questionário para definir a preferência do estilo de aprendizagem entre visual, auditivo, leitura/escrita e sinestésico; optou-se pelos Estilos de aprendizagem de Felder-Soloman (EAFS)(1991) apresentado a seguir.

O Índice de Estilos de aprendizagem (Index of Learning Styles - ILS) foi desenvolvido por Richard M. Felder e Barbara A. Soloman baseado nos estilos de Felder e Silverman (1988). Felder e Soloman desenvolveram um instrumento para determinar as preferências de aprendizagem em quatro dimensões: ativo ou reflexivo, sensorial ou intuitivo, visual ou verbal, sequencial ou global. 
O instrumento é composto por quarenta e quatro perguntas de escolhas forçadas ( $A$ ou $B$ ) sendo 11 questões para cada dimensão. O instrumento pode ser encontrado no site da Universidade Estadual da Carolina do Norte, neste link: https://www.webtools.ncsu.edu/learningstyles/

A estrutura dos estilos de Aprendizagem (EAFS) se configuram em:

Figura 1 - Estilos de aprendizagem

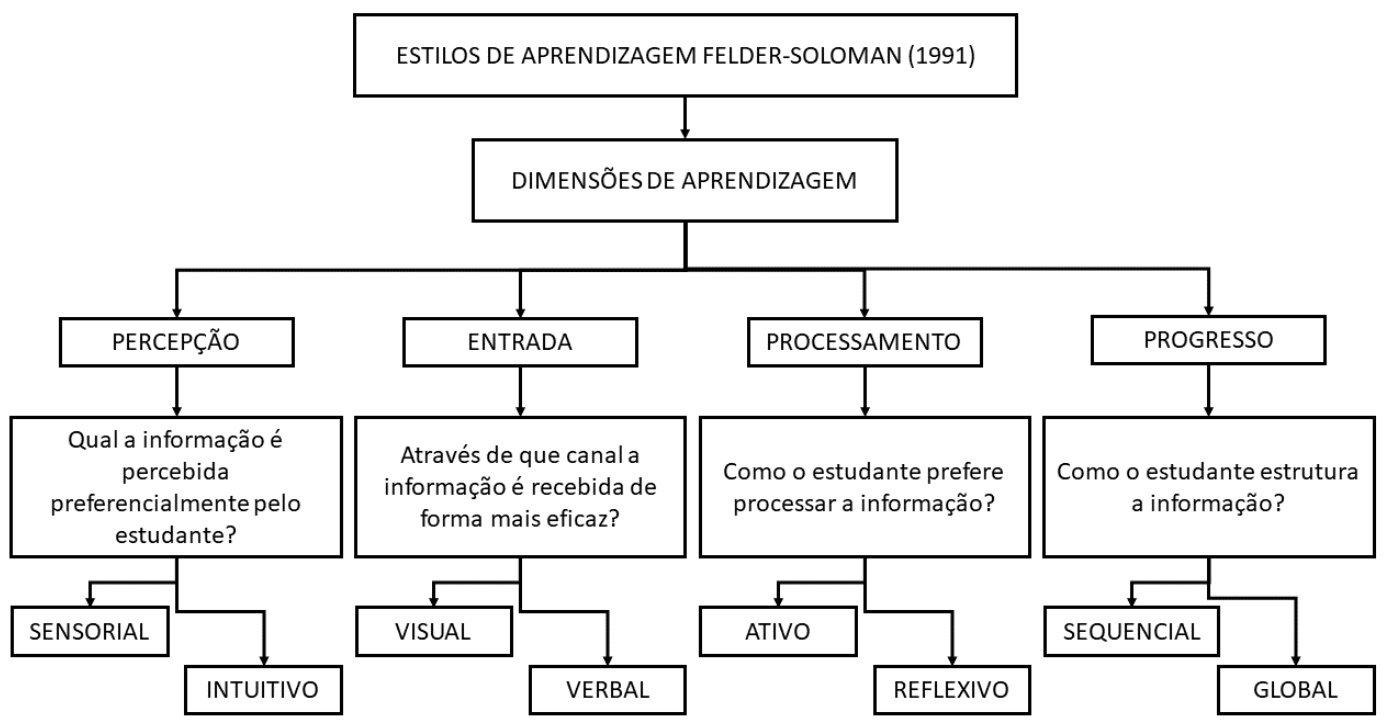

Fonte: As autoras - elaborado a partir do artigo Avaliação da utilização de recursos de ensino on-line relacionados a diferentes estilos de aprendizagem. Disponível em:

http://seer.ufrgs.br/index.php/InfEducTeoriaPratica/article/view/63305

Os estudantes Sensoriais gostam de resolver problemas através de procedimentos bem estabelecidos, enquanto os intuitivos gostam de desafios, preferem descobrir inter-relações entre elementos. Os Visuais - Preferem lidar com as representações visuais (gráficos, diagramas, vídeos, quadros) enquanto os Verbais preferem explicações escritas ou faladas à demonstração visual. Os estudantes Ativos - Tendem a processar e reter a informação participando ativamente de alguma atividade, são rápidos, mas podem ser precipitados, e gostam de trabalhar em grupo, enquanto os reflexivos, como o próprio nome diz, refletem mais sobre a informação, são mais lentos mas tendem a ser mais cuidadosos, e gostam de trabalhar individualmente. Os estudantes sequenciais obtêm entendimento em passos lineares, de forma sequencial, tendendo a seguir caminhos lógicos e graduais na solução de um problema, já os globais privilegiam o contexto, o grande quadro, tendo foco na síntese, no pensamento sistêmico.

\section{O Experimento Metodológico}

A partir da análise dos dados coletados no final de 2015, uma porta se abriu para a melhoria da qualidade do ensino aprendizagem na disciplina Arte Moderna e Contemporânea no curso de Design. A disciplina tem como ementa, o estudo da arte moderna e contemporânea como instrumento de educação do "olhar": Caracterização das concorrentes artísticas e leituras de obras de arte. E, como objetivo principal, reconhecer e compreender a arte moderna como produção do 
conhecimento (Plano de Ensino da disciplina Arte Moderna e Contemporânea - 2015/1). A disciplina é composta por um conteúdo extenso e que exige do estudante a habilidade de analisar, as diferentes manifestações culturais, os fatores de construção de identidade e de estabelecimento de diferenças sociais e históricas, a fim de, identificar procedimentos artísticos expressos em várias linguagens e os relacionar com o campo do Design.

A partir dos dados das reprovações, houve uma mudança. Em 2016, as aulas continuaram a ser ministradas em formato de sala de aula invertida com a preparação das aulas feitas pelos alunos para que fossem apresentados Seminários e debates ilustrados com imagens que são fios condutores do processo de ensino-aprendizagem. Em cada aula, um grupo de alunos apresentava as articulações entre a Arte Moderna e Contemporânea e o mundo. (Plano de Ensino da disciplina Arte Moderna e Contemporânea - 2016/1).

Para que o maior número de alunos fosse alcançado, a disciplina passou a contar com recursos de aprendizagem diferenciados baseados nas variações dos Estilos de Aprendizagem Felder e Soloman (ESFS) e com o Facebook como plataforma para troca de saberes, construindo assim um lugar de aprendizagem compartilhada e colaborativa. Um grupo no Facebook foi criado por uma aluna da turma de 2016 para que as informações pudessem alcançar os alunos inscritos na disciplina naquele semestre e para troca de materiais didáticos, reflexões e discussões.

Pouco tempo depois o grupo já se movimentava para compartilhamento de vídeos, imagens, gráficos, que acabaram sendo recursos valiosos para os debates em sala. Para contemplar as dimensões de aprendizagem estabelecidas pelos ESFS, algumas ferramentas foram trabalhadas: Mapas Mentais (Visual/Global); linha do tempo (sequencial/sensorial); vídeos (visuais/intuitivos); textos e áudios (verbal) e questionários no Google Forms (Ativo/reflexivo). Todo esse material didático era produzido e compartilhado pelo Facebook.

Tabela 1 - Evolução do Experimento Metodológico

Estilos de Aprendizagem aplicados à disciplina de Arte Moderna e Contemporânea mediados pelo Facebook

\begin{tabular}{lll}
\hline Ano & No alunos & Recursos \\
\hline 2016 & 117 & Mapas Mentais e Linha do Tempo \\
2017 & 159 & Mapas Mentais, Linha do Tempo, Seminários, vídeos, textos e áudios, Google Forms \\
2018 & 91 & $\begin{array}{l}\text { Mapas Mentais, Linha do Tempo, Seminários, vídeos, textos e áudios, Google Forms e } \\
\text { "Cardápio" (ainda em andamento). }\end{array}$ \\
\hline
\end{tabular}

Fonte: As autoras, 2018.

O Mapa Mental segundo Tony Buzan, seu criador, é uma técnica gráfica que fornece uma chave universal para desbloquear o potencial do cérebro. Ele aproveita toda a gama de habilidades corticais - palavra, imagem, número, lógica, ritmo, cor e consciência espacial. Um Mapa Mental pode ser aplicado a todos os aspectos da vida, onde o aprendizado melhorado e o pensamento mais claro, melhoram o desempenho humano (BUZAN, 2005). Com a utilização de mapas mentais, o estudante com a dimensão visual mais potencializada (EAFS) sentiu-se mais motivado a pesquisar, assim como o aluno Global, que a partir desta ferramenta, pode ter uma visão do todo e depois de cada parte dos assuntos abordados. A cada aula era construído um mapa mental com a participação 
dos estudantes que colaboravam com os resultados de suas pesquisas sobre o tema da aula.

Figura 2 - Mapa Mental construído com colaboração dos alunos

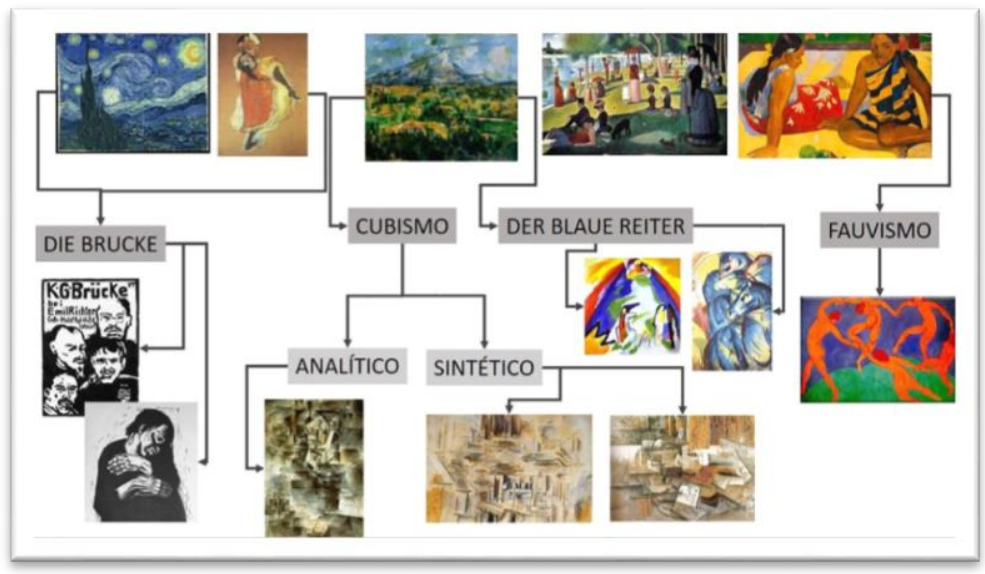

Fonte: https://www.facebook.com/groups/1026472547419575/

A linha do tempo é uma ferramenta que para os alunos sequenciais e sensoriais (EAFS) foi de grande ajuda. Os alunos sequenciais preferem ver os acontecimentos em ordem. A disciplina Arte Moderna e Contemporânea não é linear, acontecem vários movimentos artísticos ao mesmo tempo em lugares diferentes e, além disso, um movimento influencia na manifestação artística do outro. A ferramenta Linha do tempo ajudou os alunos sensoriais que aprendem melhor através de fatos e dados concretos. A partir destes dados organizados, o aluno sensorial mostrou maior compreensão dos assuntos abordados.

Figura 3 - Linha do tempo construído com colaboração dos alunos em aula

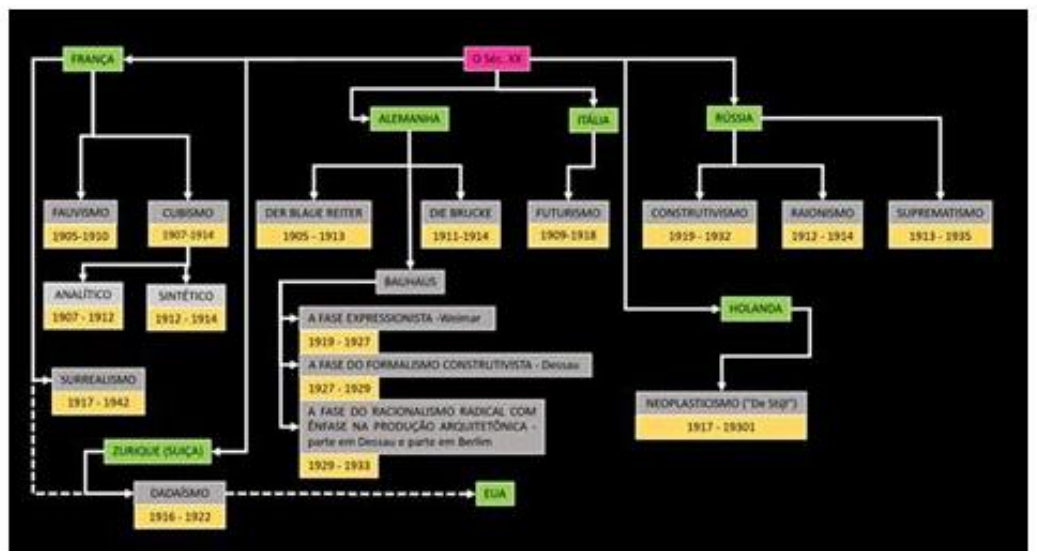

Fonte: https://www.facebook.com/groups/1026472547419575/

Neste momento do experimento, os estudantes ainda não tinham o hábito de compartilhar novas associações com os assuntos da disciplina. Pouco tempo depois entenderam que poderiam construir seu próprio caminho de aprendizagem, começaram a tecer suas relações com o campo do Design e o conhecimento passou a ser desejado. Os alunos intuitivos foram aqueles que conseguiam estabelecer mais conexões entre Arte Moderna e Contemporânea e a vida cotidiana. 
Figura 4 - Postagem de um aluno intuitivo no grupo da disciplina.

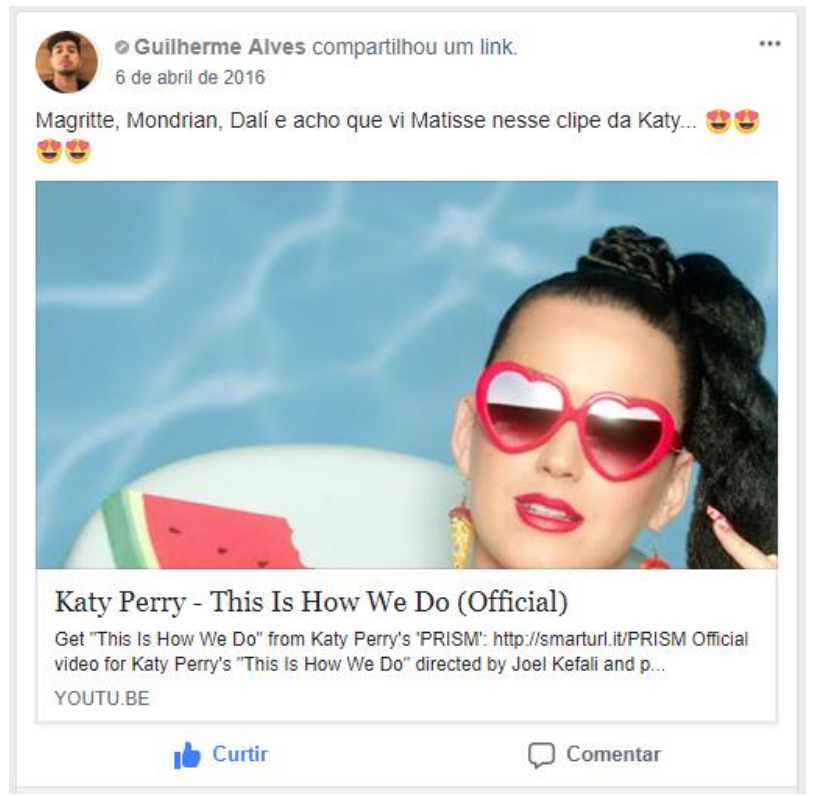

Fonte: As autoras disponível em https://www.facebook.com/groups/1026472547419575/

Estas manifestações suscitaram uma investigação mais apurada e estruturada. Neste momento foi desenvolvida uma estrutura metodológica para a disciplina.

Figura 2 - Estrutura proposta para o Experimento Metodológico

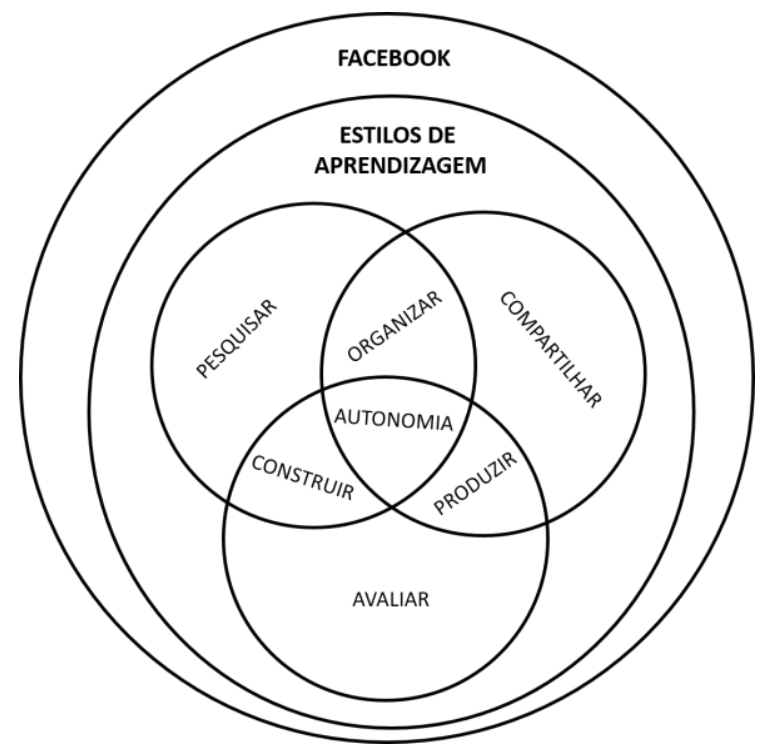

Fonte: As autoras

Esta estrutura é formada por três elementos-chaves: Pesquisar, compartilhar e avaliar que estão inseridos em um núcleo fundamentado nos estilos de aprendizagem EAFS. Cada elementochave, ao interseccionar outro elemento-chave produz uma ação. Estas ações interseccionadas com os elementos-chaves podem proporcionar a autonomia do estudante em seu processo de ensinoaprendizagem. 
A utilização desta estrutura na disciplina em questão, envolveu uma mudança nas atividades institucionais para além da dinâmica de sala de aula. No princípio alguns alunos não reconheciam o conteúdo produzido e compartilhado por eles. Ainda hoje, a maioria dos estudantes estão acostumados a entrar na sala de aula e receber um conteúdo pronto e sair como um repositório, por vezes até vazio. $O$ primeiro elemento-chave, a pesquisa, tem o objetivo uma aproximação entre aprendizagem e sociedade. Veremos como se deu esta prática no item 2.1.

A estrutura proposta conta também com um processo de compartilhamento de saberes. Proporcionar um meio pelo qual o estudante possa pensar coletivamente: compartilhar. Apontar seus pontos de vista e estar diante de outros tantos pontos de vista diferentes dos seus. Um pensar junto, um mover-se na direção da construção do conhecimento e comunicar esses achados. Para isso a estrutura contou com o apoio da rede social Facebook como plataforma de aprendizagem colaborativa. Veremos isso no item 2.2.

Para esta proposta estrutural, entender o processo de avaliar foi de suma importância, visto que quando se fala em disciplina, trata-se de um aproveitamento de créditos acadêmicos, e a preocupação do estudante com seu coeficiente de rendimentos é real. O processo de avaliação fundamentado na escolha do estudante, foi proposto para a valorização de um processo autônomo, uma tomada de consciência sobre o quem é responsável pelo próprio processo de aprendizagem. Veremos, detalhadamente este processo no item 2.3.

Como dito anteriormente, a disciplina Arte Moderna e Contemporânea é uma disciplina teórica que contou com recursos didáticos diferenciados proporcionando melhor desempenho dos estudantes que fizeram uso destes recursos. Sendo assim houve a necessidade de estruturar uma metodologia que desse continuidade a essas descobertas. A estrutura apresentada se constitui no entrelaçamento entre pesquisar, compartilhar e avaliar, que formam a tríade básica para uma proposta metodológica. E, em seus interstícios, organizar, produzir e construir nasceu uma autonomia discente.

\subsection{Pesquisar}

A Pesquisa como um dos pilares desta metodologia funcionou atrelada aos outros pilares constituindo um processo de construção do conhecimento tanto do estudante que está imerso na sua busca, quanto da sociedade que ele está inserido.

A pesquisa faz parte do processo de aprendizagem desde cedo, na vida escolar. Professores desde o ensino fundamental utilizam a pesquisa como ferramenta para gerar novos conhecimentos ou refutá-los. Elisabete Matallo Marchesini de Pádua, pesquisadora do Método na Ciência e seus desdobramentos na Metodologia Científica e na pesquisa, define assim:

\footnotetext{
Tomada num sentido amplo, pesquisa é toda atividade voltada para a solução de problemas; como atividade de busca, indagação, investigação, inquirição da realidade, é a atividade que vai nos permitir, no âmbito da ciência, elaborar um conhecimento, ou um conjunto de conhecimentos, que nos auxilie na compreensão desta realidade e, nos oriente em nossas ações (PÁDUA, 1996, p. 29).
}

Pensando com Pádua, é através da ação, que se pode construir um conhecimento capaz de dar conta da realidade, e que, por conseguinte, alterará esta realidade produzindo um novo conhecimento. A pesquisa na metodologia proposta na disciplina Arte Moderna e Contemporânea a partir dos anos 2016, coloca o estudante diante do novo, para que possa analisar, organizar e 
comparar os resultados de sua pesquisa para compartilhar com os outros estudantes a fim de cumprir a essência do pesquisar.

Os estilos de Aprendizagem Felder-Soloman (EAFS) trouxeram para o ato de pesquisar uma multiplicidade de formas atreladas às dimensões de aprendizagem e isso proporcionou ao estudante uma forma mais personalizada de pesquisa. Os estudantes intuitivos começaram a fazer associações do conteúdo da disciplina com outras áreas e campos do saber. $O$ aluno sensorial pode contribuir com dados e fatos para a construção do conhecimento. $O$ aluno ativo compartilhava muitas referências, na maioria das vezes superficiais, mas se tornava um excelente catálogo sobre o assunto, enquanto o aluno reflexivo fazia contribuições sobre o assunto com tamanha profundidade, que contagiava os outros a se aprofundarem em suas pesquisas.

Outra forma de crescimento em pesquisa através dos EAFS, foi retirando o aluno de sua zona de conforto, o próprio Richard M. Felder (1988) adverte que para haver um crescimento genuíno é necessário que se desenvolva as dimensões que não são dominantes. Para tal desenvolvimento foi proposto aos estudantes o trabalho em grupo com dimensões diferentes para que um possa aprender com o outro.

\subsection{Compartilhar}

Vivenciar as culturas digitais e incluir as tecnologias móveis na sala de aula, não é apenas usar uma nova metodologia de aprendizagem para transmitir conteúdo. É pensar nesse novo estudante, inserido culturalmente em um ambiente em que tudo acontece ao mesmo tempo, o tempo todo. Este sujeito que pensa, produz saberes e compartilha opiniões, conteúdos e informações nas redes. Há dois anos utilizo o Facebook como plataforma colaborativa de conhecimento. A comunicação foi ampliada e proporcionou a dialogicidade defendida por Paulo freire (2016, p.39):

A tarefa coerente do educador que pensa certo é, exercendo como ser humano a irrecusável prática de desafiar o educando com quem se comunica, a produzir sua compreensão do que vem sendo comunicado. Não há inteligibilidade que não seja comunicação e intercomunicação e que não se funde na dialogicidade.

A utilização do Facebook tinha como objetivo ampliar a comunicação e flexibilizar o compartilhamento de conhecimento através do imenso labirinto de possibilidades que a plataforma oferece. Os estudantes foram convidados a participar do grupo e trabalhar colaborativamente.

Em 2016, o próprio Facebook comemorava a marca de 102 milhões de brasileiros que se conectavam pelo Facebook. Desse total, 93 milhões acessam via dispositivos móveis (CLAVIJO FACEBOOK PARA EMPRESAS, 2016). O avanço da tecnologia mobile permitiu trocas quase instantâneas pelas redes sociais, facilitando a construção do conhecimento.

Michel Serres em seu livro "Polegarzinha" nos coloca diante da quebra do paradigma do local de estudo, da "escola". Diz ele:

Com o acesso pessoas pelo celular e com o acesso a todos os lugares pelo GPS, o acesso ao saber se abriu. De certa maneira, já está o tempo todo e por todo lugar transmitido. Certamente objetivado, mas, além disso, distribuído. Não concentrado. [...] A pedagogia muda completamente com as novas tecnologias. (SERRES, 2013, p. 26 e 27 - grifo nosso)

Era preciso compartilhar os olhares multifacetados. Cada um poderia contribuir com seu olhar e assim foi estabelecido um processo vivo de compartilhamento de pesquisas, resultados de investigações e trabalhos concluídos para críticas. Além disso começou a surgir espontaneamente no grupo, as chamadas "coisas interessantes". 
Essas "coisas interessantes" são as informações que os alunos sentem o desejo de compartilhar. Da sua timeline, das suas pesquisas, dos seus momentos de humor. Colocar suas palavras para serem ouvidas. Isso constituiu, neste espaço, uma ciberdemocracia. "E esse deslocamento da palavra, esse "poder de dizer enfim", esse "mostrar" e "se mostrar" generalizado é uma das principais dimensões da revolução ciberdemocrática em curso. (LEMOS e LÉVY, 2010, p.90)

O objetivo de ter um dos pilares da nova metodologia no compartilhamento é justamente promover uma comunidade ciberdemocrática, que consegue ver ideias tão diferentes das suas e manter uma dialogicidade.

Dentro da questão do compartilhamento, os EAFS revelaram as dimensões predominantes dos educandos. Os ativos postam mais, os reflexivos comentam menos, mas de forma mais aprofundada, os visuais postam imagens, memes, gifs. Os estudantes se sentiram motivados e livres para compartilhar, uma aprendizagem colaborativa.

No grupo do Facebook criado para esta disciplina, as interações foram se construindo de forma crescente. Em 2016 a interação chegava no máximo a 15 reações e pouquíssimos comentários. Como docente, uma das autoras, era a alimentadora principal das discussões e das postagens. No ano de 2017 esse número passou a ser maior, e a autora não precisava alimentar o grupo sozinha, os alunos estavam motivados a compartilhar conhecimento. $O$ ano de 2018 mostrou que com a flexibilização das propostas avaliativas, que veremos no item 3.3, e com o experimento estruturado, a interação no Facebook está sendo mais intensa. Veja o comparativo a seguir com os gráficos oferecidos pelo Facebook:

Gráfico 1 - Mapa de envolvimento dos participantes do grupo da disciplina no Facebook em 2017

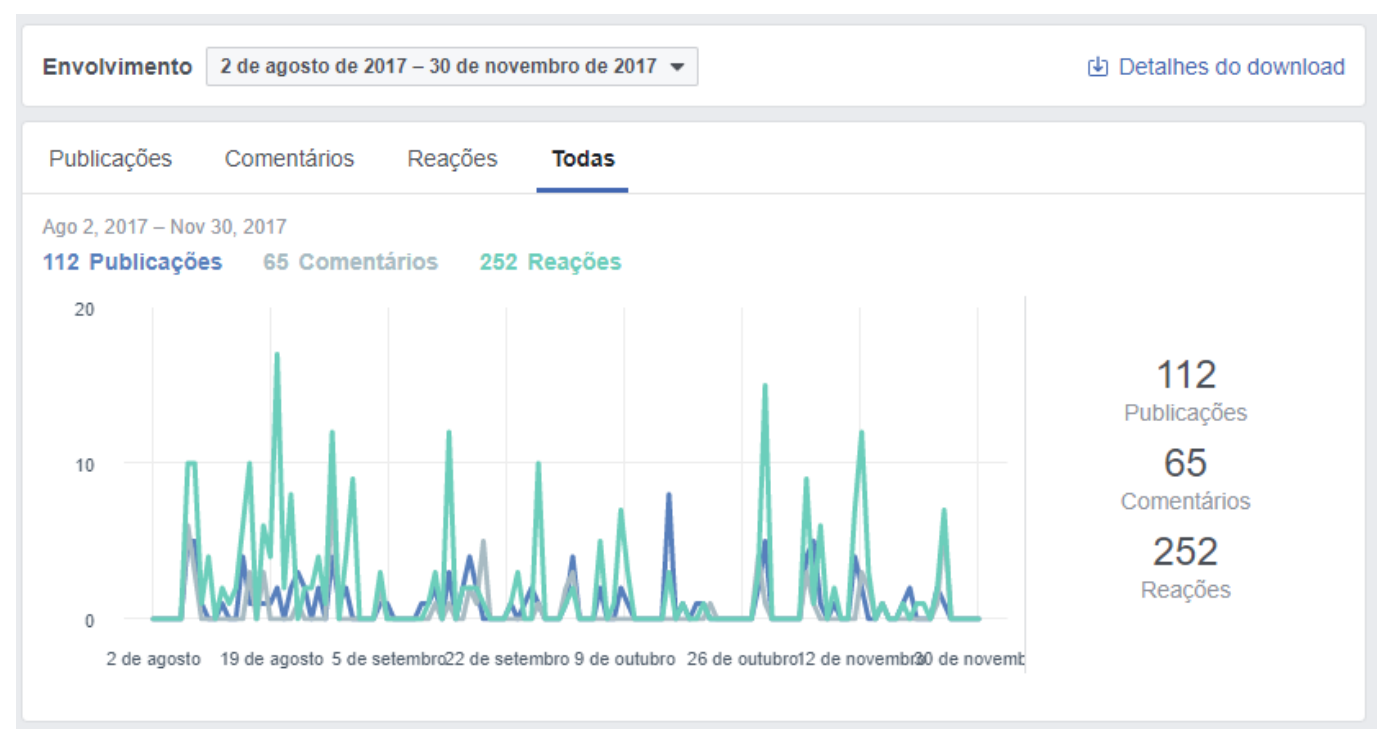

Fonte: https://www.facebook.com/groups/1026472547419575/insights/?section=engagement 
Gráfico 2 - Mapa de envolvimento dos participantes do grupo da disciplina no Facebook em 2018

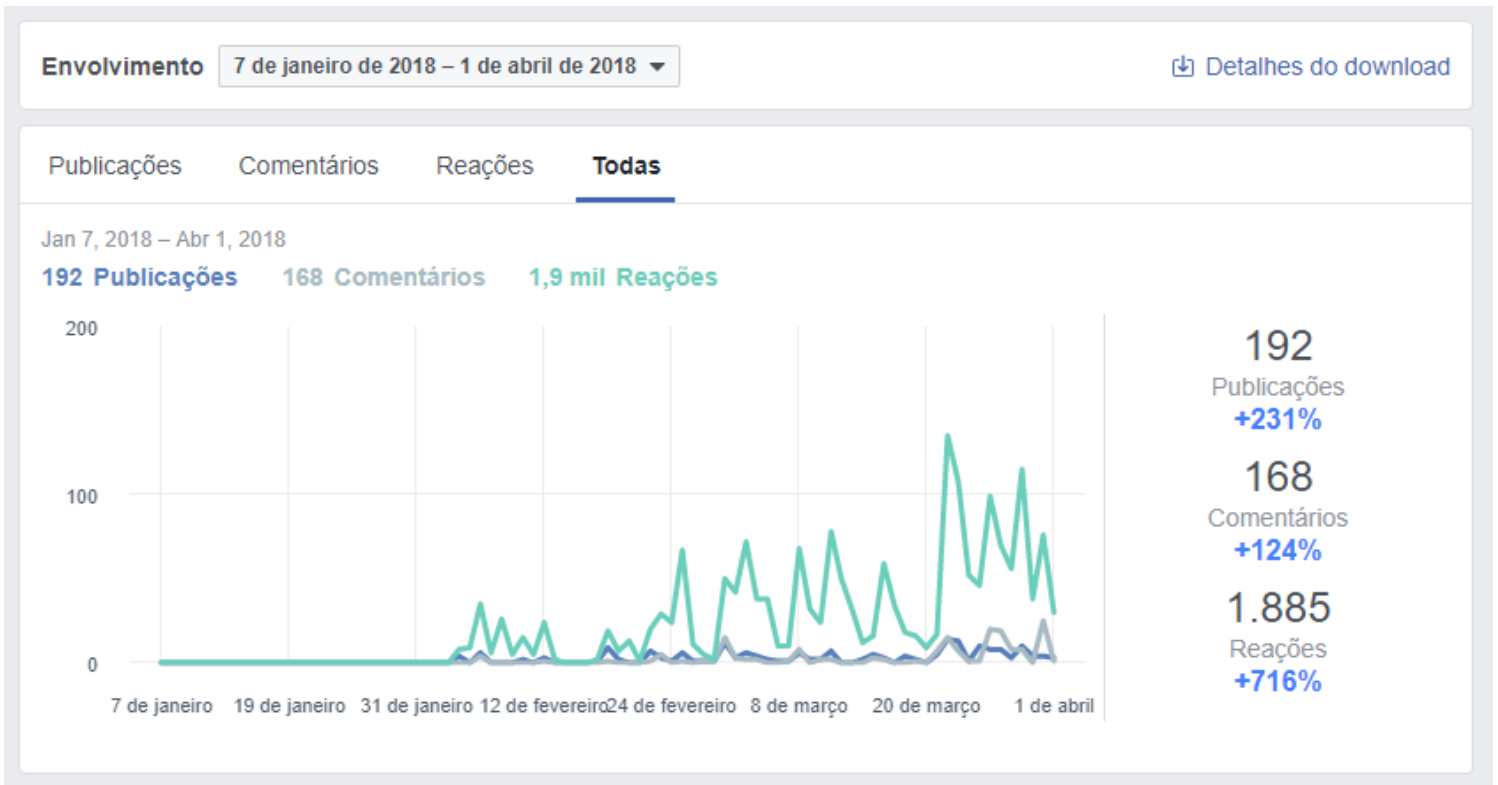

Fonte: https://www.facebook.com/groups/1026472547419575/insights/?section=engagement

\subsection{Avaliar}

Em primeiro lugar cabe diferenciar avaliar de examinar. Segundo Luckesi (2000): “A avaliação da aprendizagem, por ser avaliação, é amorosa, inclusiva, dinâmica e construtiva, diversa dos exames, que não são amorosos, são excludentes, não são construtivos, mas classificatórios. A avaliação inclui, traz para dentro; os exames selecionam, excluem, marginalizam".

No entanto, é necessário ter cuidado com o que é institucional. Para a instituição, é importante que o estudante tenha um bom aproveitamento acadêmico e demonstre isso no Exame Nacional de Desempenho de Estudantes (Enade). Se por um lado a avaliação precisa ser inclusiva, construtiva e amorosa, por outro temos o exame que avalia o rendimento dos concluintes dos cursos de graduação em relação aos conteúdos programáticos, habilidades e competências adquiridas em sua formação.

Muitas instituições treinam os estudantes para obter maior pontuação no Enade, fazem simulados, testes e questionários. Nós acreditamos no desenvolvimento de habilidades e competências ao longo do percurso acadêmico e no conhecimento que ele foi capaz de articular, desenvolver e produzir. Só assim ele será capaz de ter respostas próprias às questões propostas pelo Enade.

Por isso a avaliar é um dos elemento-chaves desta metodologia. $\mathrm{O}$ ato de avaliar deve estar diretamente ligado ao objetivo do que se pretende avaliar, não em dados secundários. Assim também deve ser o instrumento de avaliação, adequado ao que se pretende avaliar. Como dito anteriormente, avaliação não é um exame, é a forma pela qual, generosamente pode-se acolher o que não foi bem assimilado para voltar a isso com outro olhar. Avaliação é um ato de redenção tanto para o avaliador, quanto para o avaliado. Se este processo for dialógico, ambos aprendem e constroem conhecimento.

O experimento metodológico trouxe uma mudança visível para os resultados do processo avaliativo durante esses dois anos de experimento metodológico. No segundo semestre de 2015, o 
instrumento de avaliação era composto por duas provas, $70 \%$ objetivas e $30 \%$ discursivas. Do total de 71 alunos, 25 precisaram de uma prova extra e 20 não conseguiram lograr êxito. Depois do experimento estes números mudaram.

Em 2016, a avaliação passou a ser composta por duas provas, $70 \%$ objetivas e $30 \%$ discursivas, um projeto associando os conteúdos abordados na disciplina ao campo do design e um questionário online no Google Forms com questões diversificadas, atendendo às dimensões (EAFS). Dos 117 alunos inscritos na disciplina, 26 não cursaram (excederam o limite de faltas em mais de 50\%) e apenas 1 aluno foi para prova extra e não conseguiu aprovação.

Em 2017, o instrumento avaliativo passou a ser composto por duas provas, $70 \%$ objetivas e $30 \%$ discursivas. Pequenos trabalhos seguindo os estilos de aprendizagem EAFS associando os conteúdos abordados na disciplina ao campo do design. Um questionário online no Google Forms com questões diversificadas atendendo às dimensões (EAFS). Dos 158 alunos inscritos na disciplina, 19 não cursaram (excederam o limite de faltas em mais de $50 \%$ ) e apenas 13 alunos precisaram de prova extra, porém não obtiveram êxito.

A seguir podemos comparar os resultados de aprovação na disciplina em dois anos de trabalho experimental.

Quadro 1 - Análise dos resultados dos alunos entre 2015 e 2017

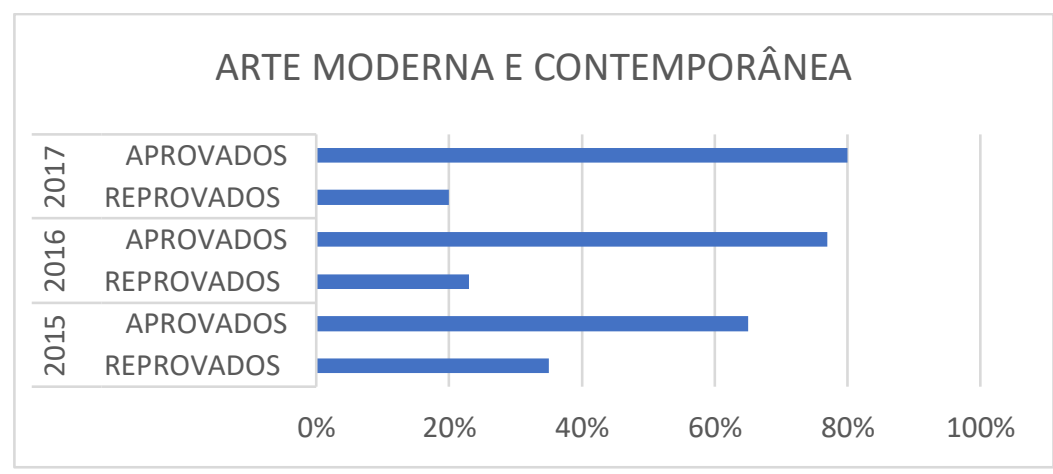

Fonte: Elaboração das autoras mediante os relatórios de faltas e notas finais da disciplina.

A crescente aprovação e a construção do saber, foram os motivos que levaram a concepção deste artigo. Na terceira parte será apontado alguns pressupostos a serem investigados na continuação desta abordagem metodológica.

\section{Conclusões}

O desenvolvimento do presente estudo possibilitou uma análise de como os estilos de aprendizagem (EAFS) ampliaram as possibilidades do processo de ensino aprendizagem dos estudantes da disciplina de Arte Moderna e Contemporânea. Além disso, também permitiu a obtenção de dados mais consistentes sobre a evolução do experimento metodológico aplicado e sua eficácia. Com a aplicação desta nova metodologia, o índice de reprovações, na disciplina estudada, diminuiu de 45,08\% (2015) para 20\% (2017) incluindo os alunos desistentes, aqueles que contabilizam mais de 50 \% de faltas. Identifica-se como possibilidade de reprovação e abandono a não adequação à metodologia por parte dos discentes, no entanto este dado será analisado em 
publicações futuras. Ao verificar estes dados, revelamos a importância e valorização dos experimentos pedagógicos no processo de ensino aprendizagem no Design.

Partindo destes resultados, em 2018, uma nova forma avaliativa está sendo testada, um "cardápio" de atividades visando contemplar cada uma das dimensões propostas pelo EAFS. Chamada de Composição livre de avaliação semestral, apelidada pelos alunos de "cardápio", termo bem adequado para um instrumento busca abarcar as individualidades de aprendizado e compreensão dos conteúdos, além da colaboração na rede social Facebook. Cada aluno poderá compor livremente sua avaliação semestral dentre as atividades listadas. Para cada uma delas, o aluno deve escolher suas atividades que possam somar 100 pontos. A entrega será on-line no grupo da disciplina no Facebook. Dentre as atividades estão: resumo, resenha, Padlet, análises, memes, músicas, filmes, visitas técnicas, projetos, maquetes, pasta pública no Pinterest, composições plásticas, dentre outras. O importante é que o aluno poderá escolher sua forma de avaliação.

Neste ano uma nova etapa foi acrescentada a este experimento, a aplicação do questionário dos estilos de aprendizagem no início do período letivo para que os discentes possam perceber seus estilos de aprendizagem, e assim, construir seu próprio caminho na produção do conhecimento.

Tabela 2 - Resultados dos Questionários aplicados

\begin{tabular}{cccccccccccc}
\hline \multicolumn{10}{c}{ Resultado dos Questionários de Perfis de Aprendizagem ESFS } \\
\hline Ano & No alunos & Visual & Verbal & Sensorial & Intuitivo & Ativo & Reflexivo & Sequencial & Global \\
\hline 2018 & 74 & 63 & 11 & 47 & 27 & 47 & 27 & 36 & 38 \\
\hline
\end{tabular}

Fonte: As autoras, 2018.

Depois desta nova etapa, o compartilhamento de conhecimento, na plataforma Facebook subiu $231 \%$ e as reações aos compartilhamentos subiram $716 \%$, segundo dados da própria plataforma apresentados nos gráficos 1 e 2 . Além disso, a criatividade nos compartilhamentos tem se acentuado, motivando novas associações entre os conteúdos da disciplina e o campo do design, imerso na cultura vigente, o que permite uma continuidade desta pesquisa por caminhos ainda desconhecidos.

Este artigo deixa como contribuição para o campo do design, a importância de ofertar diferentes recursos que contemplem todas as dimensões de aprendizagem. Experimentos e coleta de dados que validam os processos pedagógicos experimentais são essenciais na busca de inovações em contextos educacionais no campo do design.

\section{Referências}

BUZAN, Tony. Mapas mentais e sua elaboração. Editora Cultrix, 2005.

Campinas: Papirus, 1996.

CLAVIJO, Ismael Gálvez. Facebook para empresas. IC Editorial, 2016.

DUNN, R.; DUNN, K.; PRICE, G. E. Productivity environmental preference survey. Lawrence, KS: 
Price Systems, 1982.

FELDER, R. M.; SILVERMAN, L. K. Learning styles and teaching styles in engineering education. International Journal of Engineering Education, Ontario, v. 78, n. 7, p. 674-681, 1988.

FELDER, R. M.; SOLOMAN, B. A. Index of learning styles questionnaire. North Carolina State University, 1991. Disponível em: <http://www4.ncsu.edu/unity/lockers/users/f/felder/publi c/ILSdir/styles. htm>. Acesso em: 16 de março de 2018.

FLEMING, N. D. Teaching and learning styles: VARK strategies. Christchurch, New Zealand: N. D. Fleming, 2001.

FREIRE, Paulo. Pedagogia da autonomia: saberes necessários à prática educativa. 54. ed. Rio de Janeiro: Paz e Terra, 2016.

GREGORC, A. F. Learning/teaching styles: their nature and effects. NASSP Monograph, 1979.

HUNT, J. Distúrbio da Aprendizagem: Uma Rosa com Outro Nome. Psicóloga Diretora do "The Natural Child Project", 1979. Disponível em http://helenab.tripod.com/jan_hunt/distapr.htm. Acesso em: 07 de março de 2018.

KOLB, D. A. Experimental learning: experience as the source of learning and development. New Jersey: Prentice-Hall, Englewood Cliffs, 1984.

LEMOS, André; LÉVY, Pierre. 0 futuro da internet: em direção a uma ciberdemocracia planetária. São Paulo: Paulus, p. 14, 2010.

LUCKESI, Cipriano Carlos. 0 que é mesmo o ato de avaliar a aprendizagem. Revista Pátio, v. 12, p. 6-11, 2000.

NAMEN, Anderson Amendoeira et al. Avaliação da utilização de recursos de ensino on-line relacionados a diferentes estilos de aprendizagem. Informática na educação: teoria \& prática, v. 20, n. 2 mai/ago (2017).

PÁDUA Elisabete Matallo Marchesini de. Metodologia da pesquisa: Abordagem teórico-prática. SERRES, Michel. Polegarzinha. Rio de Janeiro: Bertrand Brasil, 2013. 